\title{
Muş İli İçin Optimal Hastane Yeri Seçiminin Analitik Hiyerarşi Süreci ile Değerlendirilmesi
}

\author{
Assessment of Optimal Selection of Hospital Location for Muş City by Analytical Hierarchy Process \\ Özgür Yeşilyurt a ${ }^{\text {, Fuad Selamzade }}{ }^{\text {b, * }}$ \\ ${ }^{a}$ Dr. Öğr. Üyesi, Muş Alparslan Üniversitesi, Sağlık Bilimleri Fak., Sosyal Hizmet Bölümü, o.yesilyurt@alparslan.edu.tr, 49100, Muş/Türkiye \\ ORCID: 0000-0001-9252-3375
}

${ }^{\text {b}}$ Dr. Öğr. Üyesi, Muş Alparslan Üniversitesi, Sağlık Bilimleri Fak., Sağlık Yönetimi Bölümü, f.salamov@alparslan.edu.tr, 49100, Muş/Türkiye ORCID: 0000-0002-2436-8948

\section{MAKALE BİLIISI}

Makale Geçmişi:

Başvuru tarihi: 31 Mart 2020

Düzeltme tarihi: 07 Eylül 2020

Kabul tarihi: 18 Eylül 2020

\section{Anahtar Kelimeler:}

Hastane Yer Seçimi

En Uygun Yerin Seçimi
Analitik Hiyerarşi Süreci (AHP)

ÖZ

Bu araştırmanın amacı Muş ilinde kurulması muhtemel olan bir hastanenin kuruluş yeri seçiminin analitik hiyerarşi süreci ile belirlenmesidir. Yer seçiminin yapılabilmesi için Muş ili belediyesi uzmanları ve Muş Alparslan Üniversitesi'nde görevli akademisyenlerin görüşleri anketlerle alınmıştır. Çalışmada kullanılan ana kriterler konum, altyapı özellikleri, çevre, yatırım maliyeti ve demografik yapıdır. Alt kriterler ise; merkeze yakınlık, hasta ve çalışan ulaşım kolaylığı, devlet hastanesine uzaklık durumu, geniş alan, altyapı yeterliliği, ses-gürültüye yakınlı, kar temizlenmesi, arsa maliyeti, inşaat maliyeti, nüfus yoğunluğu ve sigortalılık durumudur. Bu kriterler kullanılarak ikili karşılaştırmalar yapılmış olup, karşılaştırılan kriterler çok kriterli karar verme yöntemlerinden biri olan analitik hiyerarşi süreci tekniği kullanılarak sıralanmıştır. Araştırma Muş iline yapılması muhtemel olan bir hastanesinin literatürden yararlanılarak oluşturulmuş olan kriterlere göre en uygun yerin seçilmesi konusunda yol gösterici niteliktedir. Çalışmada hastane yer seçimi problemi için en uygun konumun \%40,81 ile Bingöl yolu (S2) bölgesi olduğu sonucuna varılmıştır.

\section{ARTICLE INFO}

Article history:

Received 31 March 2020

Received in revised form 07 September 2020

Accepted 18 September 2020

\section{Keywords:}

Hospitan Location Selection

Analytic Hierarchy Process (AHP)

Selection of the Most Suitable Location

\section{A B S T R A C T}

The purpose of this study is to determine the establishment location of a hospital which is probably to be founded in Muş City by analytic hierarchy process. In order to select the location, opinions of the experts of the Muş city municipality and the academicians working at the Muş Alparslan University have been taken with questionnaires. Main criteria used in the study are location, features of infrastructure, environment, investment cost and demographic structure. Sub criteria are proximity to the city center, patient and employee accessibility, distance to public hospital, large land area, infrastructure adequacy, proximity to sound-noise, snow clearing, land cost, construction cost, population density and insurance status. Binary comparisons have been made using these criteria and compared criteria have been listed using the analytical hierarchy process technique, which is one of the multi-criteria decision making methods. This study has a guiding nature in selecting of the most suitable location according to the criteria established by using the literature of any hospital that is likely to be built in Muş. In the study, it was concluded that the most suitable location for the problem of selecting hospital location is the Bingöl road (S2) region with $40.81 \%$.

\section{Giriş}

İşletmeler kuruluş yeri seçimiyle işletmenin faaliyette bulunduğu hayat alanının da sınırlarını çizmektedirler. Bundan dolayı kuruluş yeri rastgele seçilmemeli, yer seçimi kararlarında dar görüşlü olunmamalı ve duygusal davranılmamalı, işletme büyüklüğü ve işletmenin çalışma konusu dikkate alınmalıdır. Kuruluş yeri seçimi kararıyla ilgili alternatif yerlerin özellikleri birbirleriyle karşılaştırılarak karar verilmelidir (Şimşek ve Çelik, 2014: 84). Bir hastane yeri seçimini etkileyen çevresel, ekonomik, politik ve sosyal faktörler bulunmaktadır. Hastane yeri seçimini etkileyen bu faktörlerin bilincinde olmak kurulacak olan hastanenin başarısını etkileyen unsurlar

\footnotetext{
* Sorumlu yazar/Corresponding author.

e-posta: f.salamov@alparslan.edu.tr
} 
arasında yer almaktadır. Yer seçimi kararının statik bir karar olmadığı unutulmamalıdır. Diğer bir ifadeyle; kuruluş aşamasında çevresel, ekonomik, politik ve sosyal faktörlere uygun olan bir yerin yıllar sonra aynı özelliklerini koruyamaması doğal bir durumdur (Üreten, 2006: 326).

Sağlık kurumuna olan talep yeterli düzeydeyse veya mevcut hastane sağlık hizmetlerine olan talebi karşılayamıyorsa yeni bir hastaneye ihtiyaç doğmaktadır. Kuruluş yeri kararları uzun vadeli kaynak tahsisi gerektiren stratejik niteliği olan kararlardır (Ozcan, 2009: 82). Sağlık kurumuna ihtiyacın (talebin) belirlenmesinde, toplumun demografik özellikleri ve hastalıkların prevalansı faktörler etkili olmaktadır.

Çalışma Muş ili sınırlarında belirlenmiş olan alternatifler arasında kurulması muhtemel olan hastane kuruluş yerlerinin seçiminde yol gösterici olması için yapılmıştır.

Çok kriterli karar verme yöntemlerinden biri olan Analitik Hiyerarşi Süreci (AHP) yöntemi kullanılarak bu çalışma yapılmıştır. $\mathrm{Bu}$ kapsamda literatürde yer alan akademik çalışmalardan bazıları aşağıdaki gibidir:

Wu vd. (2007) Tayvan hastaneleri için yaptığı çalışmada, faktör koşulları, talep koşulları, firma stratejisi yapısı ve rekabet koşulları, bağlantılı ve destekleyici endüstriler, hükümet ve şans kriterlerini kullanmışlardır.

Aydın vd. (2009) çalışmasında, Ankara için en uygun yerleşim alternatifleri olarak, farklı coğrafi konumlarındaki ilçeler; Konutkent, Sincan, Altındağ, Ankara Merkez ve Çankaya bölgeleri incelenmiş, ölçüt faktörleri olarak bina özellikleri, rekabet unsurları, yatırım maliyetleri, bina konumu ve demografik yapı ele alınarak en uygun yerin Sincan olduğu sonucuna varılmıştır.

Chatterjee ve Mukherjee (2013) yaptı̆̆ Hindistan 'da hastane yeri seçiminin değerlendirilmesi için tanımlanan kriterler arasında en önemli faktörlerin yer maliyeti, nüfus yoğunluğu ve ulaşım olduğu sonucuna varmıştır.

Bakan (2014) çalışmasında, 12 ilçe (Ceyhan, Nazilli, Bandırma, İnegöl, Lüleburgaz, Akhisar, Turgutlu, Kızıltepe, Siverek, Cizre, Çorlu, Ereğli) alternatifi arasından sosyo-ekonomik gelişmişlik, şehirleşme oranı, fert başına bütçe geliri, akademik birim sayısı, en yakın üniversiteye mesafe, lisans yerleştirme oranı ve lise öğrenci sayısı kriterlerine göre üniversite kurulması gerekli olan en uygun ilçe AHP yöntemi ile belirlenmeye çalışılmış, çalışma sonucunda \%20 ağırlık derecesi ile Bandırma ilçesi en iyi alternatif olarak belirlenmiştir.

Gencan (2014) çalışmasında, Analitik Hiyerarşi Prosesi (AHP) ve Veri Zarflama Analizi (VZA) yöntemlerini kullanarak Ankara'da faaliyet gösteren 26 kamu hastanesinin performansını değerlendirmiştir. Çalışma sonucunda ağırlık kısıtlamasız VZA modelinde 13, ağırlık kısıtlamalı VZA modelinde ise 10 hastanenin etkin olduğu görülmüştür.

Paköz (2015) çalışmasında, İstanbul'da sağlık arzı ile talebi arasındaki ilişkinin hastanelere erişim ve mekânsal erişilebilirlik üzerinden irdelenmesi, hastanelerin ilçe bazında optimum mekânsal dağılımının ve yer seçiminin sayısal tekniklerle modellenmesi amaçlanmıştır.
İnce vd. (2016) yaptıkları çalışmada, İstanbul ili Tuzla ilçesinde kurulması düşünülen özel sağlık kuruluşu için en iyi yer seçimi probleminin çözümü için, bina konum ve özellikleri, çevresel faktörler, rekabet unsuru, demografik yap1, bina konumu ve yatırım maliyetleri kriterleri kullanarak dört bölge seçeneği oluşturmuştur. Çalışma sonucunda \%36 ile en fazla ağırlık değerine sahip olan bölgenin seçilmesi uygun görülmüştür.

Aladağ vd. (2017) yaptıkları çalışmada, müşteri memnuniyeti, fiyatlandırma politikası, teknik kalite ve bilinirlik kriterlerine göre 4 alternatif hastanenin karşılaştırılması sonucunda, en iyi hastanenin D hastanesi olduğuna kararına varmışlardır.

Şahin vd. (2019) çalışmada, 6 kriter ile Muğla ’nın 12 ilçesi içerisinde hastane yerinin seçimi için en iyi ilçenin Bodrum olduğu tespit edilmiştir.

Ajaj vd. (2019) İrak’ın Kerkük şehrinde hastane kuruluş yerinin seçimi için AHP ve Coğrafi Bilgi Sistemleri yöntemlerini kullanmıştır.

Sonel vd. (2019) Türkiye'de sağlık turizmi için tercih edilen şehirler arasında seçim ve analiz analitik hiyerarşi prosesi, analitik ağ süreci ve DEMATEL yöntemleri kullanılarak yapılmıştır. Çalışma sonucunda Mersin şehrinin ekonomik olarak İstanbul'a göre daha uygun olduğu ve iyileştirmeler yapılmasının gerekliliği sonucuna varılmıştır.

Erdal ve Yumurtacı Aydoğmuş. (2019) çalışmasında, ihracat süreçlerinin daha başarılı bir şekilde yönetilmesi ve ihracat potansiyelinin arttırılabilmesi açısından İstanbul Tekstil ve Konfeksiyon İhracatçı Birlikleri tarafindan yönetilecek bir lojistik merkezin kurulacağ1 uygun yerin AHP yaklaşımı ile belirlenmesi amaçlanmıştır. İkili karşılaştırmalar sonucunda alternatifler arasından en uygun yer seçilmiştir.

Doğan ve Akbal (2019) çalışmasında hem hasta hem de hastane açısından en uygun tedarikçi seçim kararının verilebilmesi için çok kriterli karar verme yöntemlerinden biri olan AHP yöntemini kullanılmıştır. Çalışma Niğde ilinde faaliyet gösteren bir üniversite hastanesinin satın alma birim yöneticilerinin bakış açısıyla medikal firmalar arasından en uygun tedarikçinin seçilmesi amacıyla yapılmıştır. Çalışmanın sonunda bir üniversite hastanesi için medikal firma seçiminde etkili olan kriterler belirlenmiş ve bu kriterler medikal firmalar arasında karşılaştırılarak bir sonuca varılmıştır.

Çalışmada ilgili literatür göz önünde bulundurularak AHP yönteminin yer seçim problemlerinde yaygın olarak kullanıldığı görülmüştür. Bu sebeple Muş ili için kurulması muhtemel hastane yerinin belirlenmesinde AHP yöntemi bu çalışmada kullanılmıştır. İlgili literatürden hareketle ana kriter ve alt kriterler hazırlanmıştır. Belirlenmiş olan kriterlere göre hastane kurulması düşünülen yer alternatiflerinin karşılaştırılması uzmanlara sorulmuştur. Uzmanlara anket yöntemiyle alternatif kuruluş yerlerini kriterlere göre karşılaştırmaları istenmiştir. Karşılaştırma sonucunda ortaya çıkan verilerle çalışma yapılmıştır.

\section{Analitik Hiyerarşi Süreci (AHP)}

Analitik Hiyerarşi Süreci, 1970'li yılların sonunda geliştirilmiş olan karmaşık problemlerin çözümünde 
kullanılan çok kriterli karar verme yöntemlerinden biridir (Gürsakal, 2015 :256).

Tablo 1'de AHP yönteminde alternatiflerin ve kriterlerin ikili karşılaştırma değerleri verilmiştir.

Tablo 1. İkili Karşılaştırma Skalası

\begin{tabular}{lll}
\hline & Tanım & Açılama \\
\hline 1 & Eşit öneme sahip & Her iki kriter de eşit öneme sahip \\
\hline 2 & Zayıf ya da hafif & \\
\hline 3 & Biraz önemli & $\begin{array}{l}\text { Bir kriter diğerine göre biraz daha } \\
\text { önemli sayılmıştır }\end{array}$ \\
\hline 4 & Makul artı & \\
\hline 5 & Fazla önemli & $\begin{array}{l}\text { Bir kriter diğerine göre çok daha } \\
\text { önemli sayılmıştır }\end{array}$ \\
\hline 6 & Güçlü artı & \\
\hline 7 & Çok fazla önemli & $\begin{array}{l}\text { Kriter diğer kritere göre kesinlikle çok } \\
\text { daha önemli sayılmışır }\end{array}$ \\
\hline 8 & Çok çok güçlü & \\
\hline 9 & Son derece önemli & $\begin{array}{l}\text { Bir kriterin diğerine göre son derece } \\
\text { önli olduğu bazı bilgilere } \\
\text { dayandırılmaktadır. }\end{array}$ \\
\hline
\end{tabular}

Kaynak: Saaty, 2008: 86.

Kriterler ve alt kriterlerle ilgili karşılaştırma yapılırken kullanılmış olan adımlar ve formüller şunlardır (Yaralığlu, 2010: 42-48).

Adım 1: Karar verme problemi tanımlanmalıdır.

Adım 2: Faktörler arasındaki (A) karşılaştırma matrisleri oluşturulmalıdır. Ana köşegen altında kalan değerler için (1) numaralı formül kullanılmaktadır.

$a_{j i}=\frac{1}{a_{i j}}$

Adım 3: Faktörlerin yüzde önem dağılımları hesaplanmalıdır. Sütun vektörlerinin hesaplanmasında (2) numaralı formül kullanılmaktadır. Yukardaki adımlar her bir kriter için yapıldığında kriter sayısı kadar B sütun vektörü oluşmaktadır.

$b_{i j}=\frac{a_{i j}}{\sum_{i=1}^{n} a_{i j}}$

$\mathrm{n}$ adet $\mathrm{B}$ sütun vektörü bir matris formatında yazıldığında $\mathrm{C}$ matrisi ortaya çıkmaktadır. Kriterlerin birbirine göre önem değerlerini gösteren W öncelik vektörü (3) hesaplanmasinda numaralı formül kullanılmaktadır.

$w_{i}=\frac{\sum_{i=1}^{n} c_{i j}}{n}$

Adım 4: Faktör kıyaslamalarındaki tutarlılık durumu ölçülmelidir. Bunun için de öncelikle A karşılaştırma matrisi ile $\mathrm{W}$ öncelik vektörünün çarpılmasıyla D sütun vektörü ortaya konulmalıdır. Tutarlılık oranı hesaplamasının özünü faktör sayısı ve temel değer adı verilen $(\lambda)$ bir katsayının karşılaştırılması oluşturmaktadır. Temel değerin hesaplanmasında (4) ve (5) numaralı formül kullanılmaktadır. ( $\lambda$ ) hesaplandıktan sonra tutarlılık göstergesinin hesaplanmasinda (6) numaralı formül kullanılmaktadır. Rassal indeks (RI) olarak adlandırılan (Tablo 2'de gösterilmiş olan) standart düzeltme değerlerine bölünerek tutarlılık oranı hesaplamasında (7) numaralı formül kullanılmaktadır.

$E_{i}=\frac{d_{i}}{w_{i}} \quad(i=1,2,3, \ldots, \mathrm{n})$

$\lambda=\frac{\sum_{i=1}^{n} E_{i}}{n}$

Tutarlılık İndeksi: $\mathrm{CI}=\frac{\lambda-n}{n-1}$

Tutarlılık Oranı: $\mathrm{CR}=\frac{C I}{R I}$

Adım 5: Her bir faktör için karar noktalarındaki yüzde önem dağılımları hesaplanmalıdır.

Adım 6: Karar noktasındaki sonuç dağılımı bulunmalıdır.

Muş'ta kurulması muhtemel hastanenin yerinin belirlenmesinde hangi semtin en iyi olduğunun tespiti için aşağıdaki formül (8) kullanılmıştır. $\mathrm{Bu}$ formülde bütün kriterlerin ve semtlerin ağırlıklarının hesaplanmasından sonra, her bir semtin farklı kriterlerin ağırlıkları ile kriterlerin genel ağırlıkları çarpılmış ve en yüksek ağırlığa sahip olan semt tespit edilmiştir (Aydın vd., 2009: 79).

Semt Ağırlığ $1=\quad \mathrm{A} 1 *(\mathrm{~A} 11 * \mathrm{~S}+\mathrm{A} 12 * \mathrm{~S}+\mathrm{A} 13 * \mathrm{~S})+$

$$
\begin{aligned}
& +\mathrm{A} 2 *(\mathrm{~A} 21 * \mathrm{~S}+\mathrm{A} 22 * \mathrm{~S})+ \\
& +\mathrm{A} 3 *(\mathrm{~A} 31 * \mathrm{~S}+\mathrm{A} 32 * \mathrm{~S})+ \\
& +\mathrm{A} 4 *(\mathrm{~A} 41 * \mathrm{~S}+\mathrm{Ad} 2 * \mathrm{~S})+ \\
& +\mathrm{A} 5 *(\mathrm{~A} 51 * \mathrm{~S}+\mathrm{A} 52 * \mathrm{~S})
\end{aligned}
$$

Burada, "A1 -Ana kriterler aras1 ağırlı̆̆ı", "A11 - Alt kriterler arası ağırlığı" ve "S - alt kritere göre ilgili semtin ağırlığı"dır.

Tablo 2'de Rassal İndeks (RI) değerleri yer almaktadır.

Tablo 2. Rassal İndeks Değerleri

\begin{tabular}{cccc}
\hline $\mathbf{N}^{*}$ & $\mathbf{R I}$ & $\mathbf{N}^{*}$ & $\mathbf{R I}$ \\
\hline $\mathbf{1}$ & 0,00 & $\mathbf{6}$ & 1,25 \\
\hline $\mathbf{2}$ & 0,00 & $\mathbf{7}$ & 1,35 \\
\hline $\mathbf{3}$ & 0,52 & $\mathbf{8}$ & 1,40 \\
\hline $\mathbf{4}$ & 0,89 & $\mathbf{9}$ & 1,45 \\
\hline $\mathbf{5}$ & 1,11 & $\mathbf{1 0}$ & 1,49 \\
\hline
\end{tabular}

$\mathrm{N}^{*}$ : Kriter Matrisi ve Karar Alternatif Sayıs1

Kaynak: Önder ve Güler, 2014: 33.

Tutarlılık oranı 0,1'den küçükse iyi (kabul edilebilir seviye) olarak adlandırılmaktadır. Tutarlılık oranının 0,1 'den büyük çıkması durumunda tutarlılık oranı için yeniden değerlendirme yapılması (karşılaştırma matrisinin güncellenmesi) gerekmektedir (Hafeez vd., 2002: 43).

Grup kararlarının oluşturulmasında en iyi yol olarak Saaty (2008) yapmış olduğu çalışmasında bireysel tercihlerin geometrik ortalamalarının alınması gerektiği ifade etmiştir (Saaty, 2008: 95).

\section{Yöntem ve Uygulama}

$\mathrm{Bu}$ çalışmada, Muş`ta inşa edilmesi muhtemel olan bir hastane için uygun yerin seçilmesinin tahmin edilmesi amaçlanmıştır. Bunun için Muş Belediyesi uzmanları ve 
Muş Alparslan Üniversitesi akademisyenlerini kapsayan uzmanların alternatiflerin incelenmesi için görüşü alınarak AHP analiz yöntemi ile tahminler yapılmıştır. Alternatifler belirlenirken şehrin konumu ve büyüme durumları göz önünde bulundurularak oluşturulmuştur.

Hastane yerinin seçilmesi için Muş Alparslan Üniversitesi Külliyesi (S1), Bingöl yolu üzerindeki alan (S2), şehir merkezi de sayılabilecek yer olan Muş Tren Garı mevki (S3) ve Bitlis yolu üzerindeki boş alan (S4) alternatif kuruluş yeri olarak seçilmiştir.

Muş Alparslan Üniversitesi Külliyesi Diyarbakır Kulp yolu üzerinde olup, merkezden $7 \mathrm{~km}$ batıda yer almakta, iki tarafinda köy bulunmaktadır.
Bingöl Yolu üzerinde bulunan Muş Alparslan Üniversitesi yerleşkesi benzer coğrafi konuma sahip olup, Muş`un kuzeyinde yer alan bir semttir. Yeni Muş otogarı bu güzergahta bulunmaktadır.

Muş Tren Garı Yeşilce mevki Muş merkeze daha yakın bir semt olup, Tren Gar istasyonu yakınlarında yer almaktadır.

Son alternatif olarak Muş`un doğusunda, şehir çıkışında Bitlis yolu üzerinde bulunan boş alan seçilmiştir. Bu yol üzerinde Muş Devlet Hastanesi ve Muş Sultan Alparslan Havalimanı da bu güzergahta bulunmaktadır.

Şekil 1'de çalışmaya konu olan alternatiflerin yerleri gösterilmiştir.

Şekil 1. Alternatiflerin Harita Üzerinde Görünümü

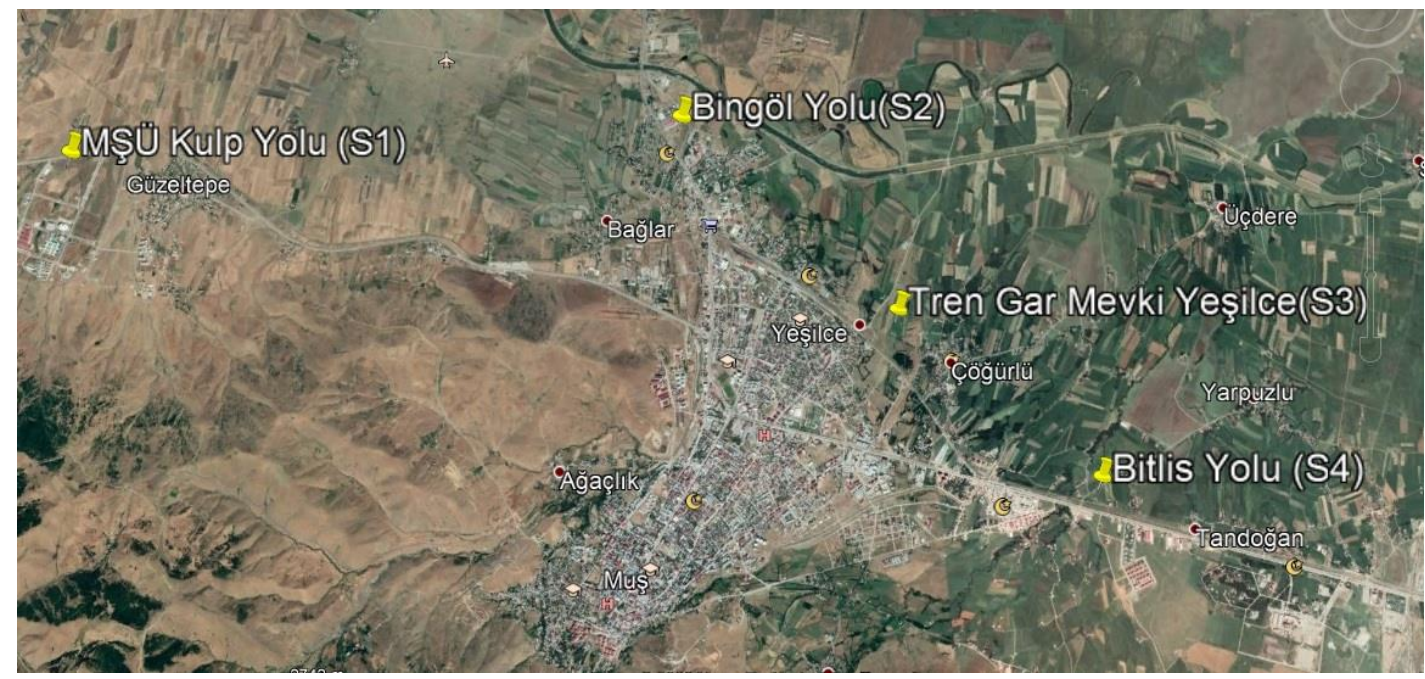

Şekil 2. Hastane Yeri Seçiminde Kullanılan Kriterler ve Alt Kriterler

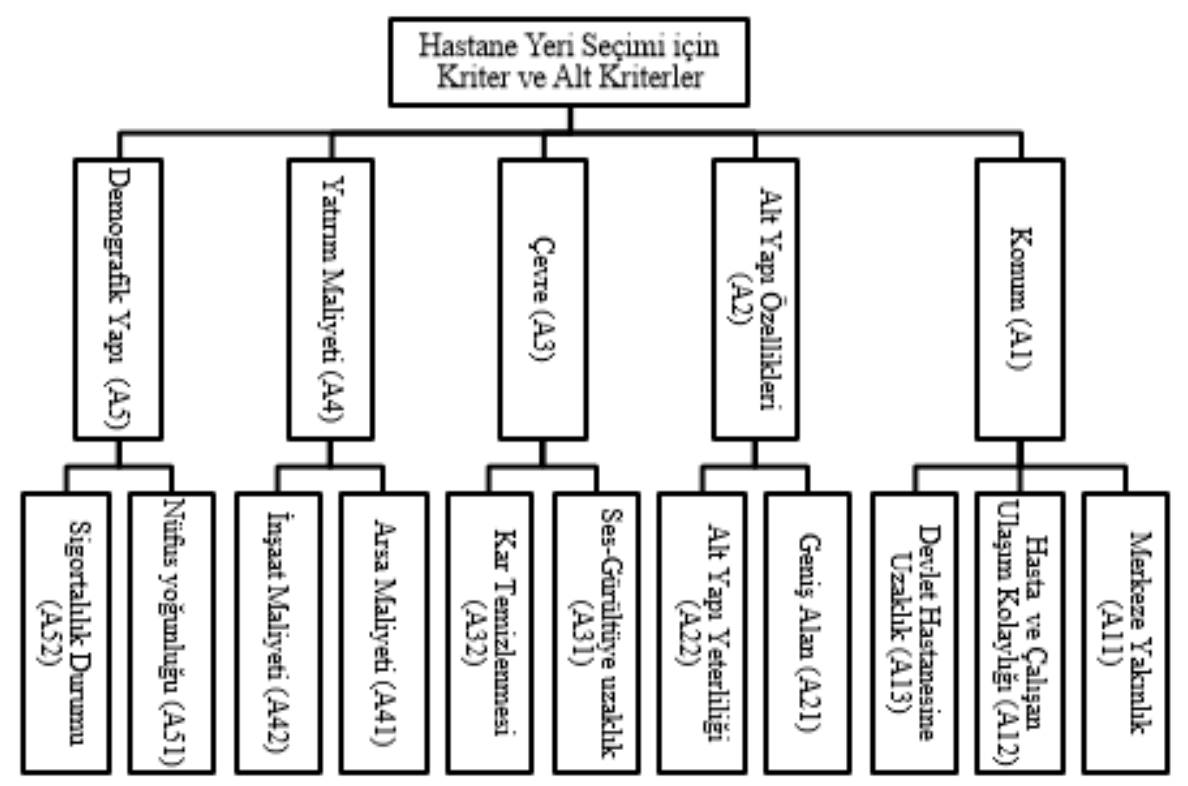

Şekil 2'de belirlenmiş olan kriter ve alt kriterlerin hiyerarşisi yer almaktadır. Çalışmada kullanılan kriterler ve alt kriterler Aydın vd. (2009) ve İnce vd. (2016) çalışmalarından Muş şartlarına uygun uyarlanarak düzenlenmiştir. 
Daha sonra Muş İ Sağlik Müdürlüğü, Muş Belediyesindeki ilgili uzmanlar ve Muş Alparslan Üniversitesi akademisyenlerine anketlerin yüz-yüze doldurulması için müracaat edilmiştir. Muş İl Sağlık Müdürlüğü'nde çalışan uzmanlar çalışmaya destek olma konusunda kararsız kalmışlardır. Bu yüzden Muş İl Sağlık Müdürlüğü'nde çalışan uzmanlar çalışmaya dahil edilmemiştir.

Çalışma için Muş Alparslan Üniversitesi Bilimsel Araştırma ve Yayın Etiği Kurulu'na başvurulmuştur. Kurulun 02/03/2020 tarihli ve 3 sayılı toplantısında alınan 13 numaralı kararınca uygun bulunmuştur.

\section{Bulgular}

Çalışmada Muş Belediyesi uzmanları (5 uzman) ve Muş Alparslan Üniversitesi akademisyenleri (5 uzman) ile yapılmış ikili karşılaştırmalı anket sonuçlarının geometrik ortalamaları alınarak nihai tablolar düzenlenmiştir. Çalışmada kullanılan ana kriterler ve alt kriterlerin ağırlıkları ve matrislerin tutarlılık oranları literatürdeki formüller kullanılarak Excel programında hesaplanmıştır.

Tablo 3`te konum (A1), altyapı özellikleri (A2), çevre (A3), yatırım maliyeti (A4) ve demografik yap1 (A5) ana kriterlerinin ikili karşılaştırmalarının geometrik ortalamaları, normalize değerleri ve satır (ağırlık) ortalamaları sunulmuştur. Uzman ve akademisyenlerin görüşlerine göre Muş ilinde kurulması muhtemel olan bir hastane için belirlenmiş ana kriterler arasında çok az fark olduğu görüşü hâkim olmuştur. Uzman ve akademisyen görüşlerine göre hastane kurulmasında en önemli kriter konum $(\% 26,2)$ ve altyapı özellikleri $(\% 24,9)$ olmuştur. Bu matrisin tutarlılık oranı 0,023 olarak hesaplanmıştır.

Tablo 3. Ana Kriterlerin İkili Karşılaştırmaları ve Ağırlıklar

\begin{tabular}{|c|c|c|c|c|c|c|}
\hline $\begin{array}{c}\text { Ana } \\
\text { Kriterler }\end{array}$ & A1 & $\mathrm{A} 2$ & $\mathrm{~A} 3$ & A4 & A5 & $\begin{array}{c}\text { Satır } \\
\text { Ortalaması }\end{array}$ \\
\hline $\begin{array}{l}\text { Konum } \\
\text { (A1) }\end{array}$ & $\begin{array}{c}1 \\
(0,262)\end{array}$ & $\begin{array}{c}1,327 \\
(0,322)\end{array}$ & $\begin{array}{c}1,558 \\
(0,242)\end{array}$ & $\begin{array}{c}1,012 \\
(0,199)\end{array}$ & $\begin{array}{c}2,324 \\
(0,284)\end{array}$ & 0,262 \\
\hline $\begin{array}{l}\text { Altyapı } \\
\text { Özelliği } \\
\text { (A2) }\end{array}$ & $\begin{array}{c}0,753 \\
(0,198)\end{array}$ & $\begin{array}{c}1 \\
(0,243)\end{array}$ & $\begin{array}{c}1,627 \\
(0,253)\end{array}$ & $\begin{array}{l}1,808 \\
(, 356)\end{array}$ & $\begin{array}{c}1,605 \\
(0,196)\end{array}$ & 0,249 \\
\hline Çevre (A3) & $\begin{array}{c}0,642 \\
(0,168)\end{array}$ & $\begin{array}{c}0,615 \\
(0,149) \\
\end{array}$ & $\begin{array}{c}1 \\
(0,155) \\
\end{array}$ & $\begin{array}{c}0,596 \\
(0,117) \\
\end{array}$ & $\begin{array}{c}1,746 \\
(0,214) \\
\end{array}$ & 0,161 \\
\hline $\begin{array}{l}\text { Yatırım } \\
\text { Maliyeti } \\
\text { (A4) }\end{array}$ & $\begin{array}{c}0,988 \\
(0,259)\end{array}$ & $\begin{array}{c}0,553 \\
(0,134)\end{array}$ & $\begin{array}{c}1,678 \\
(0,261)\end{array}$ & $\begin{array}{c}1 \\
(0,197)\end{array}$ & $\begin{array}{c}1,495 \\
(0,183)\end{array}$ & 0,207 \\
\hline $\begin{array}{l}\text { Demografik } \\
\text { yap1 (A5) }\end{array}$ & $\begin{array}{c}0,430 \\
(0,113)\end{array}$ & $\begin{array}{c}0,623 \\
(0,151)\end{array}$ & $\begin{array}{c}0,573 \\
(0,089)\end{array}$ & $\begin{array}{c}0,669 \\
(0,132)\end{array}$ & $\begin{array}{c}1 \\
(0,122)\end{array}$ & 0,121 \\
\hline
\end{tabular}

Parantez içerisinde ikili karşılaştırma matrislerinin normalize değerleri sunulmuştur.

CI - Tutarlık İndeksi; RI - Rassal İndeks; CR - Tutarlık Oranı

Tablo 4'te kurulması muhtemel bir hastane yerinin belirlenmesi için ana kriterlerden ilki olan "Konum" kriterlerinin alt kriterleri sırasıyla; merkeze yakınlık (A11), ulaşım (A12) ve Muş Hastanesi'ne uzaklık (A13) olmakla, uzman ve akademisyenler tarafindan yapılmış olan ikili karşılaştırmalarının geometrik ortalamaları yer almaktadır. Matrise göre en önemli alt kriter \%64,4'lük önem derecesi ile ulaşım olmuştur. $\mathrm{Bu}$ matrisin tutarlılık oranı 0,021 olarak hesaplanmıştır.
Tablo 4. Konum Kriterinin Alt Kriterlerine Göre Karşılaştırılması ve Ağırlıklar

\begin{tabular}{|c|c|c|c|c|}
\hline Alt Kriterler & A11 & A12 & A13 & Satır Ortalaması \\
\hline $\begin{array}{l}\text { Merkeze } \\
\text { Yakınlık (A11) }\end{array}$ & $\begin{array}{c}1 \\
(0,229)\end{array}$ & $\begin{array}{c}0,333 \\
(0,219)\end{array}$ & $\begin{array}{c}2,776 \\
(0,304)\end{array}$ & 0,251 \\
\hline Ulaşım (A12) & $\begin{array}{c}3,003 \\
(0,688)\end{array}$ & $\begin{array}{c}1 \\
(0,658)\end{array}$ & $\begin{array}{c}5,346 \\
(0,586)\end{array}$ & 0,644 \\
\hline $\begin{array}{l}\text { Muş Hastanesine } \\
\text { Uzakl1k (A13) }\end{array}$ & $\begin{array}{r}0,360 \\
(0,083) \\
\end{array}$ & $\begin{array}{c}0,187 \\
(0,123) \\
\end{array}$ & $\begin{array}{c}1 \\
(0,110)\end{array}$ & 0,105 \\
\hline \multicolumn{5}{|c|}{$\mathrm{CI}(3)=0,011 ; \mathrm{RI}(3)=0,52 ; \mathrm{CR}(3)=0,021 \leq 0,1$} \\
\hline \multicolumn{5}{|c|}{$\begin{array}{l}\text { Parantez içerisinde ikili karşılaştırma matrislerinin normalize } \\
\text { değerleri sunulmuştur. } \\
\text { CI - Tutarlık İndeksi; RI - Rassal İndeks; CR - Tutarlık Oranı }\end{array}$} \\
\hline
\end{tabular}

Tablo 5'te ana kriterlerden ikincisi olan "Altyapı Özelliği” kriterinin alt kriterleri sırasıyla; geniş alan (A21) ve altyap1 yeterliliği (A22) olmakla, uzman ve akademisyenler tarafından yapılmış olan ikili karşılaştırmalarının geometrik ortalamaları yer almaktadır. Matrise göre en önemli alt kriter \%58,6'l1k önem derecesi ile altyap1 yeterliliği olmuştur. Bu matrisin tutarlılık oranı 0,00 olarak hesaplanmıştır.

Tablo 5. Altyapı Özelliği Kriterinin Alt Kriterlerine Göre Karşılaştırılması ve Ağırlıkları

\begin{tabular}{lccc}
\hline Alt Kriterler & A21 & A22 & Satır Ortalamas1 \\
\hline Geniş Alan (A21) & $\begin{array}{c}1 \\
(0,414)\end{array}$ & $\begin{array}{c}0,705 \\
(0,414)\end{array}$ & 0,414 \\
\hline $\begin{array}{l}\text { Altyap1 Yeterliliği } \\
\text { (A22) }\end{array}$ & $\begin{array}{c}1,418 \\
(0,586)\end{array}$ & $\begin{array}{c}1 \\
(0,586)\end{array}$ & 0,586 \\
\hline \multicolumn{4}{c}{$\mathrm{CI}(3)=0,00 ; \mathrm{RI}(3)=0,52 ; \mathrm{CR}(3)=0,00<0,1$}
\end{tabular}

Parantez içerisinde ikili karşılaştırma matrislerinin normalize değerleri sunulmuştur.

CI - Tutarlık İndeksi; RI - Rassal İndeks; CR - Tutarlık Oranı

Tablo 6'da ana kriterlerden üçüncüsü olan "Çevre" kriterinin alt kriterleri sırasıyla; ses-gürültüye uzaklık (A31) ve kar temizliği (A32) olmakla, uzman ve akademisyenler tarafindan yapılmış olan ikili karşılaştırmalarının geometrik ortalamaları yer almaktadır. Matrise göre en önemli alt kriter \%63,1'lik önem derecesi ile kar temizliği olmuştur. Bu matrisin tutarlılık oranı 0,00 olarak hesaplanmıştır.

Tablo 6. Çevre Kriterinin Alt Kriterlerine Göre Karşılaştırılması ve Ağırlıkları

\begin{tabular}{lccc}
\hline Alt Kriterler & A31 & A32 & Satır Ortalamas1 \\
\hline $\begin{array}{l}\text { Ses-Gürültüye } \\
\text { uzaklık (A31) }\end{array}$ & $\begin{array}{c}1 \\
(0,369)\end{array}$ & $\begin{array}{c}0,586 \\
(0,369)\end{array}$ & 0,369 \\
\hline $\begin{array}{l}\text { Kar Temizliği } \\
(\text { A32) }\end{array}$ & $\begin{array}{c}1,707 \\
(0,631)\end{array}$ & $\begin{array}{c}1 \\
(0,631)\end{array}$ & 0,631 \\
\hline \multicolumn{4}{c}{ CI $(3)=0,00 ;$ RI $(3)=0,52 ;$ CR $(3)=0,00 \leq 0,1$} \\
\hline
\end{tabular}

Parantez içerisinde ikili karşılaştırma matrislerinin normalize değerleri sunulmuştur.

CI - Tutarlık İndeksi; RI - Rassal İndeks; CR - Tutarlık Oranı

Tablo 7'de ana kriterlerden dördüncüsü olan "Yatırım Maliyeti" kriterinin alt kriterleri sirasıyla; arsa maliyeti (A41) ve inşaat maliyeti (A42) olmakla, uzman ve akademisyenler tarafindan yapılmış olan ikili karşılaştırmalarının geometrik ortalamaları yer almaktadır. 
Matrise göre en önemli alt kriter \%52,7'lik önem derecesi ile inşaat maliyeti olmuştur. $\mathrm{Bu}$ matrisin tutarlılık oranı 0,00 olarak hesaplanmıştır.

Tablo 7. Yatırım Maliyeti Kriterinin Alt Kriterlerine Göre Karşılaştırılması ve Ağırlıkları

\begin{tabular}{lccc}
\hline Alt Kriterler & A41 & A42 & Satır Ortalamas1 \\
\hline $\begin{array}{l}\text { Arsa Maliyeti } \\
\text { (A41) }\end{array}$ & $\begin{array}{c}1 \\
(0,473)\end{array}$ & $\begin{array}{c}0,896 \\
(0,473)\end{array}$ & 0,473 \\
\hline $\begin{array}{l}\text { İnşaat Maliyeti } \\
\text { (A42) }\end{array}$ & $\begin{array}{c}1,116 \\
(0,527)\end{array}$ & $\begin{array}{c}1 \\
(0,527)\end{array}$ & 0,527 \\
\hline \multicolumn{4}{c}{ CI $(3)=0,00 ;$ RI (3) $=0,52 ;$ CR $(3)=0,00 \leq 0,1$} \\
\hline
\end{tabular}

Parantez içerisinde ikili karşılaştırma matrislerinin normalize değerleri sunulmuştur.

CI - Tutarlık İndeksi; RI - Rassal İndeks; CR - Tutarlık Oranı

Tablo 8'de ana kriterlerin beşincisi olan "Demografik Yapı" kriterinin alt kriterleri sırasıyla; nüfus yoğunluğu (A51) ve sigortalılık durumu (A52) olmakla, uzman ve akademisyenler tarafindan yapılmış olan ikili karşılaştırmalarının geometrik ortalamaları yer almaktadır.
Matrise göre en önemli alt kriter \%25,8'lik önem derecesi ile inşaat maliyeti olmuştur. $\mathrm{Bu}$ matrisin tutarlılık oranı 0,00 olarak hesaplanmıştır.

Tablo 8. Demografik Yapı Kriterinin Alt Kriterlerine Göre Karşılaştırılması ve Ağırlıkları

\begin{tabular}{lccc}
\hline Alt Kriterler & A51 & A52 & Satır Ortalamas1 \\
\hline $\begin{array}{l}\text { Nüfus yoğunluğu } \\
\text { (A51) }\end{array}$ & $\begin{array}{c}1 \\
(0,742)\end{array}$ & $\begin{array}{c}2,875 \\
(0,742)\end{array}$ & 0,742 \\
\hline $\begin{array}{l}\text { Sigortalılık } \\
\text { Durumu (A52) }\end{array}$ & $\begin{array}{c}0,348 \\
(0,258)\end{array}$ & $\begin{array}{c}1 \\
(0,258)\end{array}$ & 0,258 \\
\hline \multicolumn{2}{c}{ CI $(3)=0,00 ;$ RI $(3)=0,52 ;$ CR $(3)=0,00 \leq 0,1$} \\
\hline
\end{tabular}

Parantez içerisinde ikili karşılaştırma matrislerinin normalize değerleri sunulmuştur.

CI - Tutarlık İndeksi; RI - Rassal İndeks; CR - Tutarlık Oranı

Tablo 9'da ana kriterlerin, alt kriterlerin ve hastane konumu için uygun görülen semtlerin ağırlıklı ortalama değerleri sunulmuştur. Tablo 8 `den görüldüğü üzere Bingöl yolu güzergahında devlet hastanesine uzaklık durumu alt kriteri diğer kriterlere göre en düşük ağırlığa sahip kriter olmuştur.

Tablo 9. Semt ve Alt Kriterlerin İkili Karşılaştırmaları Sonucu Elde Edilmiş Ağırlıklar

\begin{tabular}{|c|c|c|c|c|c|c|}
\hline $\begin{array}{c}\text { Ana } \\
\text { Kriterler }\end{array}$ & Alt Kriterler & $\begin{array}{l}\text { Alt Kriterler } \\
\text { Arası Ağırlık }\end{array}$ & $\begin{array}{l}\text { MŞÜ } \\
\text { Kulp } \\
\text { Yolu }\end{array}$ & $\begin{array}{l}\text { Bingöl } \\
\text { Yolu }\end{array}$ & $\begin{array}{l}\text { Bitlis } \\
\text { Yolu }\end{array}$ & $\begin{array}{c}\text { Tren Gar } \\
\text { Mevki Yeşilce }\end{array}$ \\
\hline \multirow{3}{*}{$\begin{array}{l}\text { Konum } \\
(0,262)\end{array}$} & Merkeze Yakınlık & 0,251 & 0,075 & $\mathbf{0 , 5 0 1}$ & 0,159 & 0,264 \\
\hline & $\begin{array}{l}\text { Hasta ve Çalışan } \\
\text { Ulaşım Kolaylığ1 }\end{array}$ & 0,644 & 0,072 & 0,464 & 0,165 & 0,299 \\
\hline & $\begin{array}{l}\text { Devlet Hastanesine } \\
\text { Uzaklık Durumu }\end{array}$ & 0,105 & 0,159 & 0,295 & $\mathbf{0 , 2 9 7}$ & 0,249 \\
\hline Altyapı Özellikleri & Geniş Alan & 0,414 & 0,143 & 0,464 & 0,270 & 0,124 \\
\hline$\left(0,249^{\prime}\right)$ & Altyapı Yeterliliği & 0,586 & 0,113 & 0,439 & 0,166 & 0,282 \\
\hline \multirow{2}{*}{$\begin{array}{c}\text { Çevre } \\
(0,161)\end{array}$} & $\begin{array}{l}\text { Ses-Gürültüye } \\
\text { Yakınlık }\end{array}$ & 0,369 & 0,225 & 0,328 & 0,314 & 0,132 \\
\hline & Kar Temizlenmesi & 0,631 & 0,119 & 0,451 & 0,208 & 0,222 \\
\hline Yatırım Maliyeti & Arsa Maliyeti & 0,473 & 0,362 & $\mathbf{0 , 3 3 7}$ & 0,196 & 0,105 \\
\hline$(0,207)$ & İnşaat Maliyeti & 0,527 & 0,158 & 0,351 & 0,269 & 0,222 \\
\hline \multirow{2}{*}{$\begin{array}{c}\text { Demografik Yap1 } \\
(0,121)\end{array}$} & Nüfus Yoğunluğu & 0,742 & 0,129 & 0,328 & 0,237 & 0,306 \\
\hline & Sigortalılık Durumu & 0,258 & 0,093 & 0,345 & 0,239 & 0,322 \\
\hline
\end{tabular}

Tablo 10'da, Tablo 8`de sunulmuş semtlere ait ana kriter ve alt kriterlerin ağırlıkları ile (8) numaralı formülde gösterildiği şekilde hesaplama sonucunda elde edilmiş semtlerin ağırlık ölçümü sonuçları sunulmuştur.

Tablo 10. AHP Analizi Sonucuna Göre Belirlenmiş Hastane Yeri

\begin{tabular}{|c|c|c|c|}
\hline MSÜ & Bingöl & Bitlis Yolu & Tren Gar Mevki \\
\hline $\begin{array}{l}\text { Kulp Yolu } \\
\text { (S1) }\end{array}$ & $\begin{array}{l}\text { Yolu } \\
\text { (S2) }\end{array}$ & $\begin{array}{l}\text { Üzeri } \\
\text { (S4) }\end{array}$ & $\begin{array}{c}\text { Yeşilce } \\
\text { (S3) }\end{array}$ \\
\hline$\% 14,52$ & $\% 40,81$ & $\% 21,57$ & $\% 23,09$ \\
\hline
\end{tabular}

$\mathrm{Bu}$ sonuçlara göre Muş ilinde kurulması muhtemel bir hastane için en uygun yerin Bingöl yolu olarak bulunmuştur.

\section{Sonuç}

Çalışmada, çok kriterli karar verme yöntemlerinden biri olan Analitik Hiyerarşi Süreci (AHP) kullanılarak Muş ilinde gelecekte kurulması muhtemel olan bir hastane için yer seçimi yapılması amaçlanmıştır.
Yer seçiminin belirlenmesi için Muş Belediyesi uzmanları ve Muş Alparslan Üniversitesinde görevli akademisyenlerin görüşüne başvurulmuştur. Çalışmada kullanılacak kriterlerin seçiminde literatür incelenerek Muş şartlarına uygun kriterler belirlenmiştir. Çalışmada ana kriterler olarak konum, altyapı özellikleri, çevre, yatırım maliyeti ve demografik yapı belirlenmiştir. Alt kriterler olarak; merkeze yakınlık, hasta ve çalışan ulaşım kolaylığı, devlet hastanesine uzaklık durumu, geniş alan, altyapı yeterliliği, ses-gürültüye yakınlık, kar temizlenmesi, arsa maliyeti, inşaat maliyeti, nüfus yoğunluğu ve sigortalılık durumu belirlenmiştir.

Uzman ve akademisyen görüşlerine başvurularak elde edilen sonuçlara göre, en önemli ana kriter konum $(\% 26,2)$ ve altyapı özellikleri $(\% 24,9)$ olmuştur. Alt kriterlerden ise ulaşım kolaylığı $(\% 64,4)$, altyapı yeterliliği $(\% 58,6)$, kar temizliği $(\% 63,1)$, inşaat maliyeti $(\% 52,7)$ ve nüfus yoğunluğu $(\% 74,2)$ en önemli kriter olarak seçilmiştir.

Ana kriterler, alt kriterler ve semtlerin ağırlıklarının hesaplanması ile elde edilen sonuca göre $\% 40,81$ 'lik oran ile Bingöl yolu kurulması muhtemel olan bir hastane için en 
uygun yer olarak seçilmiştir. Seçilen semt alan genişliği, Muş şehirler arası otogarına yakınlığı ve şehirlerarası yol üzerinde bulunması itibarı ile daha uygun olduğu görüşü hâkim olmuştur.

\section{Kaynakça}

Ajaj, Q. M., Shareef, M. A., Jasim, A. T., Hasan, S. F., Noori, A. M. ve Hassan, N. D. (2019), An AHP-based GIS for a New Hospital Site Selection in the Kerkuk Governorate, 2 nd ICECCPCE19, Mosul, Iraq, 176181.

Aladağ, Z., Avcı, S., Çelik, B. ve Alkan, A. (2017), Özel Hastane Seçim Kriterlerinin Analitik Hiyerarşi Prosesi ile Değerlendirilmesi ve Kocaeli İli Uygulaması, ISITES2017 Bakü-Azerbaycan, 179-188.

Aydın, Ö., Öznehir, S. ve Akçalı, E. (2009), Ankara için Optimal Hastane Yeri Seçiminin Analitik Hiyerarşi Süreci ile Modellenmesi, Süleyman Demirel Üniversitesi İktisadi ve İdari Bilimler Fakültesi Dergisi,14 (2), 69-86.

Bakan, H. (2013). Analitik Hiyerarşi Yöntemiyle Üniversite Kurulması Uygun Olan İlçelerin Belirlenmesi. Ekonomi ve Yönetim Araştırmaları Dergisi, 2(2), 4366

Chatterjee, D. ve Mukherjee, B. (2013), Potential Hospital Location Selection using AHP: A Study in Rural India, International Journal of Computer Applications, 71(17), 1-7. DOI: 10.5120/12447-9144

Doğan, N. ve Akbal, H. (2019). Sağlık Sektöründe Tedarikçi Seçim Kararının AHP Yöntemi ile İncelenmesi: Bir Üniversite Hastanesi Örneği. Manisa Celal Bayar Üniversitesi Sosyal Bilimler Dergisi, 17(4), 440-456. DOI: 10.18026/cbayarsos.664380.

Erdal, H. ve Yumurtacı Aydoğmuş, H. (2019). Analitik Hiyerarşi Süreci ile Lojistik Merkezi Yeri Seçimi. Anemon Muş Alparslan Üniversitesi Sosyal Bilimler Dergisi, 7 (6), 129-136 . DOI: 10.18506/anemon.506321.

Gencan, S. (2014), Hastanelerin Performansının Veri Zarflama Analizi/Analitik Hiyerarşi Prosesi Bütünleşik Yöntemi Kullanılarak Değerlendirilmesi, Yüksek Lisans Tezi. Nevşehir: Nevşehir Hacı Bektaş Veli Üniversitesi.
Gürsakal, S. (2015), Çok Kriterli Karar Verme Yöntemleri, (Karar Verme, Editörler: Mustafa Aytaç, Necmi Gürsakal). 1. Baskı, Dora Yayıncılık, Bursa.

Hafeez, K. Zhang, Y. ve Malak, N. (2002). Determining key Capabilities of a Firm Using Analytic Hierarchy Process. International Journal of Production Economics, 76(1), 39-51.

İnce, Ö., Bedir, N, ve Eren, T. (2016), Hastane Kuruluş Yeri Seçimi Probleminin Analitik Hiyerarşi Süreci ile Modellenmesi: Tuzla İlçesi Uygulaması, Gazi Üniversitesi Sağlık Bilimleri Dergisi, 1(3), 08-21.

Ozcan, Y. A. (2009), Quantitative Methods in Health Care Management: Techniques and Applications. 2. Bask1, John Wiley \& Sons. USA.

Önder, G. ve Güler, E. (2014), Analitik Hiyerarşi Süreci, (İşletmeciler, Mühendisler ve Yöneticiler için Operasyonel, Yönetsel ve Stratejik Problemlerin Çözümünde Çok Kriterli Karar Verme Yöntemleri, Editörler: Bahadır Fatih Yıldırım ve Emrah Önder), 1. Bask1, Dora Yayıncılık, Bursa.

Paköz, M. Z. (2015), Sağllk Hizmetlerine Erişim ve Hastane Yer Seçimi: Istanbul Örneği, Doktora Tezi. İstanbul: İstanbul Teknik Üniversitesi.

Saaty, T. L. (2008). Decision Making with the Analytic Hierarchy Process, Int. J. Services Science, 1(1), 8398.

Sonel, E, Gür, Ş, Eren, T. (2019). Çok Ölçütlü Karar Verme ile Sağlık Turizminde Şehir Seçimi ve Analizi. Uluslararası Global Turizm Araştırmaları Dergisi, 3(1), 27-39.

Şahin, T., Ocak, S. ve Top, M. (2019), Analytic Hierarchy Process for Hospital Site Selection, Health Policy and Technology, 8 (1), 42-50.

Şimşek, M. Şerif ve Çelik, A. (2014). İşletme Bilimine Giriş, 21. Baskı. Eğitim Yayınevi. Konya.

Üreten, S. (2006), Üretim Işslemler Yönetimi Stratejik Kararlar ve Karar Modelleri, 5. Bask1, Gazi Kitabevi, Ankara.

Wu, C. R., Lin, C. T. ve Chen, H. C. (2007), Optimal Selection of Location for Taiwanese Hospitals to Ensurea Competitive Advantage by Using the Analytic Hierarchy Process and Sensitivity Analysis, Building and Environment, 42(3), 1431-1444

Yaralıŏlu, K. (2010), Karar Verme Yöntemleri, 1. Baskı, Detay Yayıncilik, Ankara. 